\title{
CULTIVATING SELF-BELIEF IN STUDENTS
}

\author{
Denise Harber ${ }^{1}$, \& Gavin Jinks ${ }^{2}$ \\ ${ }^{I}$ D. Harber Education Consultant Ltd, England (United Kingdom) \\ ${ }^{2}$ School of Allied Health and Social Care, University of Derby, England (United Kingdom)
}

\begin{abstract}
The two presenters have very different backgrounds. Gavin Jinks is a senior lecturer in social work. Denise Harber has been a teacher, head-teacher and school adviser. Both have concluded that the ability to create self-belief in a student group, be they primary school pupils or students in higher education, is fundamental to their achievements. Gavin has been the project leader for an award winning student mentoring project on the BA Applied Social Work at the University of Derby. Denise Harber was an adviser on a team that designated a primary school in the south of England as a 'cause for concern'. She then took on the role of Head-teacher and led the school to be designated as good in a subsequent Ofsted inspection. Underpinning both of these pieces of work was a commitment to develop the self-belief of the students. This was seen as being a fundamental building block in bringing about real change in the achievements of both the students and the pupils concerned. This workshop will explore how Gavin and Denise went about these pieces of work. They will explore the transferability of these ideas to other educational settings and situations, particularly settings with traditionally low academic engagement. They will also be encouraging participants to consider how it might be possible for them to cultivate a culture of self-belief in their own students/pupils.
\end{abstract}

Keywords: Self-belief, cultivate, develop, fundamental, create, engagement.

\section{Introduction}

My name is Gavin Jinks. I am a Senior Lecturer in Social Work at the University of Derby. I have overall responsibility for Year 1 of the programme, as Year Tutor. In 2015 I initiated a student mentoring and peer assisted learning project in order to increase the level and varieties of support available to Year 1 students. The progress and development of this project has taught me much about the transformational power of self-belief, not least it has taught me about the power I have to influence the self-belief of students within my cohort. I am here because I want to share some of my findings and to encourage you to consider if and how you might apply these ideas in your own settings.

Denise Harber has been a teacher in primary schools in four UK local authorities, including a London borough. She has been a head-teacher in two schools, and a local authority primary adviser in two local authorities. Throughout her career Denise has maintained a keen interest in the professional development and training of teachers. She has been an Ofsted inspector and an accredited School Improvement Partner and is now an independent education consultant. She works with senior leadership teams and governors on school improvement matters and performance management. She is also the Chair of Governors in a primary school near her home in West Sussex.

Denise will briefly summarise her belief that be successful in any endeavour individuals have to commit to the objective in two ways, they have to want it, so it has to be relevant and important to them, but they also have to believe that they can be successful. She believes that too many youngsters slip through the net in school and don't achieve their full potential because of their lack of self-belief and the paucity of their own aspirations and because education policy is and has always been largely focused on the practical aspects of teaching. When attempting to tackle the problem of underachievement policy makers usually concentrate on the content of lessons and the means of delivery, or they deal with questions about how to compensate for the perceived deficits of learners. Rarely do the suggested approaches to change address the disposition of learners, in particular their confidence and aspirations or, more accurately, the absence of these. 


\section{Self-Belief}

Back in 1965 Rosenthal used some rather controversial methods to demonstrate the extent to which the expectations of students could impact on their performance. (Rosenthal, R \& Jacobson, L. 1992). If teachers were told that students were intelligent and high performing the students produced results which reflected those beliefs. And vice-versa if teachers were told that students were less intelligent and low performing. This and other pieces of research have consistently demonstrated that our surroundings are absolutely crucial to our success.

It's not our boundaries that determines our performance, it's what we believe these boundaries are. (selfication.com)

As Henry Ford said “Whether you think you can, or you think you can't-you're right."

\subsection{Exercise 1}

Identify at least one instance where you have seen the positive impact of self-belief and the negative impact of lack of self-belief in your own life. To ease you into this we will both give you examples from our own lives. You have 2 mins for this.

Followed by very brief feedback.

2.1.1. Application in schools. It is Denise's view that effective teaching has to be underpinned by good judgement. This involves collecting and analysing information about learners' interests and expectations, their prior attainment and capability and any barriers they have to learning in order to identify what they are capable of, without putting caps on their achievement or nurturing inaccessible goals and dreams. It is then about empowering learners by elevating and sponsoring their aspirations and enabling them to acquire the knowledge, understanding and skills they need to achieve what they aspire to.

In the workshop she will outline the action she took as the Headteacher of a primary school, situated in a socially and culturally diverse community, to develop the self-esteem of pupils and teachers in order to raise individuals' personal aspirations and school standards.

\subsection{Exercise 2}

Denise will invite workshop participants to reflect on the precursors of some of their own successful learning experiences. She will also make reference to some of the ways her thinking has developed recently through observing teachers in a small village school using practical strategies, influenced by 'Growth Mindset', to develop children's independence, and resilience. (mindsetworks.com).

2.2.1. Application in higher education. Much has been written about the value of student mentoring and peer assisted learning projects in higher education. Andrews, J \& Clark R (2011) have summarised much of this work. Collier, P.J. (2017) has summarised the benefits from an American H.E. perspective. Having been persuaded about the potential of such projects I introduced the idea on the BA Applied Social Work at the University of Derby in 2015. In the first year I recruited 5 student mentors to add a layer of support to that which was already available to Year 1 students. Fast forward to 2018 and we now have 42 mentors including mentors who are now employed as social workers. The support is now provided to students on all 3 years of the degree programme. Support is provided in the following ways:

- Each group has a student led Facebook group where support and advice can be sought from mentors in the year above. The Year 1 group is open from the summer before students commence their studies.

- Student induction is largely produced and presented by mentors.

- Each student in year 1 and 2 has a named mentor who they can contact for advice and support.

- Mentors who have excelled in particular modules help deliver assignment guidance to students undertaking the same modules the following year. Mentors who have developed particular skills and knowledge in certain fields assist with teaching in relation to their specialist knowledge.

The project is underpinned by partnership between myself and the mentors. All decisions about the development of the project are made jointly. A key theme has been that mentors are trusted to make decisions and to take responsibility for their input. Student feedback regarding the project has been overwhelmingly positive from both mentors and mentees. I have a huge number of emails from mentors who have said that being asked to be a mentor and being trusted to undertake roles within the project has made a huge difference to them personally and as a developing professional. 


\subsection{Exercise 3}

Identify an instance when you have seen the positive impact of one person putting faith in another. 2 mins plus 1 min feedback.

\subsection{Exercise 4}

Work in groups of 3-5 people from broadly similar work settings. Overall aim of this exercise is for participants to produce a plan of action for cultivating self-belief (10 mins):

- At least 3 ideas to take back to their workplace;

- What they hope the introduction of these ideas might achieve (Min 3 outcomes);

- 3 specific immediate steps to be taken as soon as they return to their workplace. Summing up (3 mins)

\section{References}

Andrews, A \& Clark, R. How Peer Mentoring Enhances Student Success in Higher Education (2011). Birmingham. Aston University.

Collier, P.J. (2016) Why peer mentoring is an effective approach for promoting college student success. file:///C:/Users/782457.UNIVERSITY/Downloads/21539-Article\%20Text-32021-1-1020170824.pdf Accessed 07/01/2019 8.50am.

Mueller CM1, Dweck CS. (1998) Praise for intelligence can undermine children's motivation and performance. J Pers Soc Psychol. 1998 Jul;75(1):33-52.

Rosenthal, Robert; Jacobson, Lenore (1992). Pygmalion in the classroom: teacher expectation and pupils' intellectual development (Newly expanded ed.). Bancyfelin, Carmarthen, Wales: Crown House Pub. 